\title{
Minute Times Nanogram per Milliliter
}

National Cancer Institute

\section{Source}

National Cancer Institute. Minute Times Nanogram per Milliliter. NCI Thesaurus. Code C85732.

Minutes times nanograms per milliliter. 